\title{
THE POTENTIAL OF SOLID ELECTROLYTE FROM FISH WASTE FOR BATTERY APPLICATION
}

\author{
MUHAMMAD ASHRAFF AIMAN ROSLAN ${ }^{A}$ AND NIK AZIZ NIK ALI*B \\ ${ }^{\mathrm{a}, \mathrm{b}}$ Faculty of Fisheries and Food Science, Universiti Malaysia Terengganu, Kuala Nerus, Terengganu, Malaysia \\ *Corresponding author: nikaziz@umt.edu.my
}

\begin{abstract}
This experiment was conducted to study the potential of solid electrolyte from the fish waste of Clarias gariepinus for battery application. The battery was one of the important components that supplies electrical energy to users throughout the world, and it strongly contributed to technology development in the economic sector, transportation, residential as well as agriculture. The presence of ammonia in organic fish waste could produce renewable energy and helped to reduce the use of lithium-ion batteries in modern industries. Two different parameters were being observed in this study, which was the quantity of fish and the number of the cell layer. The process of collecting the fish waste was carried out in the hatchery at Universiti Malaysia Terengganu using two methods, which were filtering and soaking. The result showed that the highest value of energy output was $0.430 \mathrm{~V}$ from waste filtering of 50 fish and $0.207 \mathrm{~V}$ from soaking in waste of $50 \mathrm{fish}$. Meanwhile, the lowest energy output was from the tank that contained ten fish with an energy output of $0.177 \mathrm{~V}$ for filtering and $0.101 \mathrm{~V}$ for soaking. Besides, for a different number of the cell layer, the highest value of energy output was $0.414 \mathrm{~V}$ at 25 layers, and the lowest voltage was $0.175 \mathrm{~V}$ at five layers. Thus, from the study was observed that the produced voltage was dependent on the quantity of fish and the number of the cell layer, when the quantity of fish and number of cell layer increases, the output energy was also increased.
\end{abstract}

Keywords: Filtering and soaking, number of cell layer, quantity of fish, solid electrolyte, voltage

\section{Introduction}

Nowadays, nearly $85 \%$ of the world's energy demand comes from the production energy of fossil fuels that are known as the most essential sources (Kumar \& Samadder, 2017). These reliable sources may be reduced over a period of time. The only way to sustain this reliable energy is to find an alternative way to produce energy. The solution for these issues is to generate reliable energy using natural resources that convert chemical to heat energy and produce waste in the form of electrical energy. The latest world issues related to waste and energy conversion technologies are the need for effective continuous energy and a negative impact on the environment caused by ineffective disposal techniques.

As a new approach to sustain the energy from natural sources, waste to energy (WTE) concept can potentially be an alternative way to provide or serve as a new way of energy production, which can continuously control and establish a stable correlation between the economy and environment (Kumar \& Samadder, 2017). Then, most importantly, energy from animal wastes would be preferred (Lazaroiu et al., 2017). Waste to energy combustion projects is expected to achieve active growth by a few more decades and can contribute to a few improvements in utilizing reusable energy for developing countries. The highest achievement in which the world energy would accomplish particularly for the power sector, is attaining renewable energy sources (Zhang et al., 2015). In theory, the transformation of waste energy into useful stored energy is beneficial for use when needed. Our society is dependent on the incineration of fossil-based fuels should be reduced because it has been made known that one of our most significant constraints globally is its reduced supply given that supply is limited but demand is very high (Olabi, 2016; 2017). 
Since Malaysia has been developed and known as a country that produces fossil fuels, we need to think of how to sustain fossil fuels. Most of the states in Malaysia utilize fossil fuels for industries such as agriculture, aquaculture and factory. There are various industries in Malaysia namely construction, factory production and aquaculture that facilitate Malaysia in becoming a developed country. The objectives of this study were to measure the electrical energy output (voltage) of solid electrolyte based on the different number of fishes and to measure the electrical energy output (voltage) of solid electrolyte based on the different number of the cell layer. In parallel with the main objective of this study was to focus on aquaculture prospects that may lead to a profitable aspect of fishrelated production. The aquaculture industries in Malaysia are continuously growing, but most of the company throws the fish waste into the drain or lets it flows into the river solely because of the perception that it is just fish waste and no other benefit. The abundance of fish wastes worldwide has an advantage of renewable energy resources which can also be exported to other countries.

\section{Materials and Methods}

\section{Procedure:}

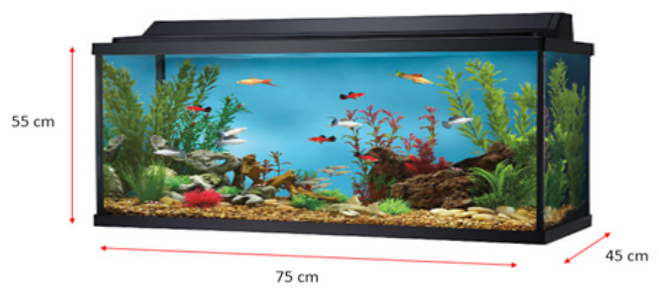

Figure 1: The aquarium size
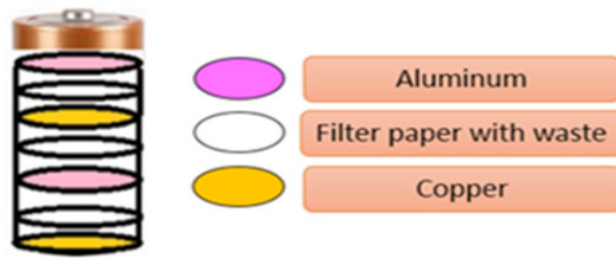

Figure 2: Materials for cell fabrication

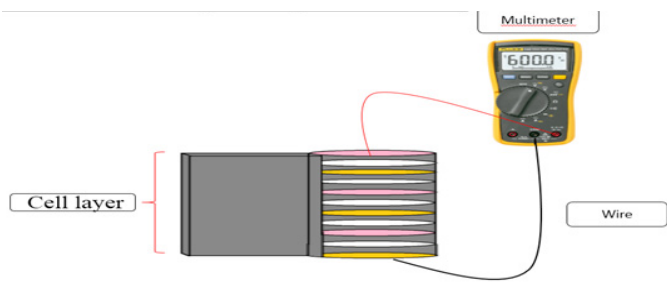

Figure 3: Output voltage measurement design

Figure 1 shows the aquarium setup for this study during the process of culturing the fish for one week. After one week, $200 \mathrm{ml}$ of fish waste was filtered using filter paper. Then, the filter paper was removed for cell fabrication. Figure 2 shows the materials used to fabricate the cell layer. Figure 3 shows the connection for output voltage measurement which is following the study's objectives where the different numbers of fish and the number of cell layers are the studied variables. Finally, all the data were recorded and tabulated for further analysis. Then, for the soaking method, that $200 \mathrm{ml}$ of fish waste was placed into a container and the filter paper was soaked in the container, then wait for 5 minutes. After 5 minutes, the filter paper was cut and fabricated into the cell layer. Figure 3 shows the same connection for output voltage measurement in accordance with the study's objectives using the same studied variables. Finally, all data were recorded and tabulated for further analysis.

According to the first objective to determine the electrical energy output (voltage) of solid electrolytes based on the different numbers of fish. The fish was cultured in five different tanks, which were equal in sizes and amount of water levels. The tanks were labeled for Tank 1, which contains 10 fishes, Tank 2 for 20 fishes, Tank 3 for 30 fishes, Tank 4 for 40 fishes, and Tank 5 for 50 fishes. The length and weight of the fish in all tanks were measured before being cultured. The average length of the fish was 5 $\mathrm{cm}$ and weight is $1 \mathrm{~g}$. The food conversion ratio was being calculated based on the weight of the fish. After one week, the water had been taken for filtering method and the soaking method by using the filter paper. For the soaking method, the filter paper was soaked into the wastewater 
for 3 minutes and wait for it to dry for another 5 minutes and been fabricated by the same number of cell layers, which were 10 layers. The cell layer was fabricated for three replicates and the average amount of voltages were being recorded. Then, the fabricated cell layer had been measured by using the voltmeter. For the filtering method, the water had been filtered by the filter paper, and then the filter was being fabricated by using copper and aluminum also in 3 replicates. Then, the cell layer was also being measured by a voltmeter to record the average amount of voltage. After one week, the cell layer had been measured again in order to examine the voltage storage either reduce or not.

Then, for the second objective, which was to measure the electrical energy output (voltage) of solid electrolytes based on the different number of the cell layers. The number of fish that being cultured was 50 fish inside a tank. The fish inside the tank was also being recorded the data of weight and length in order to give a specific amount of feed. Then, the fish were cultured for one week. The next week, the fish were taken out of the tank and the water was firstly being soaked and filtered by using the filter paper. The filter paper that being filtered and soaked were being dried for 5 minutes by using a different numbers of cell layer which were 5 layers, 10 layers, 15 layers, 20 layers and 25 layers. The cell layer was being also fabricated for three replicates and is measured by a voltmeter. After one week, the cell layer had been measured again in order to examine the voltage storage either reduce or not.

After the data being recorded based on the study's objectives, the statistical analysis had been analyzed by using One-way ANOVA because of one factor. The analysis had been done to ensure that the result achieved was significant.

\section{Results and Discussion}

\section{Results}

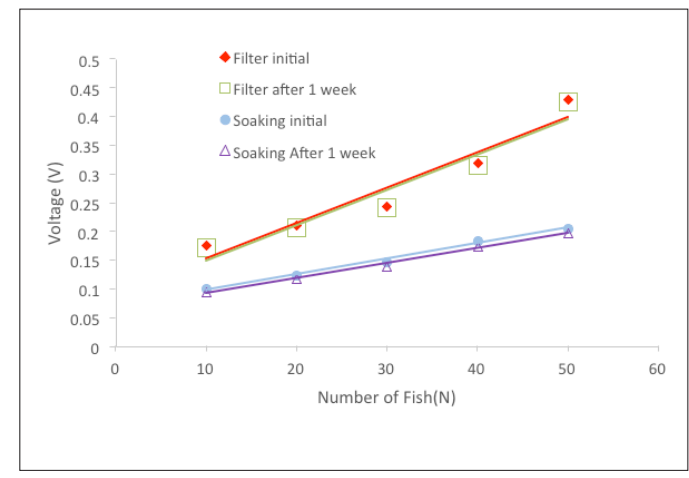

Figure 4: Electrical energy output (voltage) with the different methods used

\section{Comparison graph between the filtering and the soaking methods based on the quantity of fish}

Figure 4 was a graphical representation of electrical energy output (voltage) against the number of fishes between methods observed in this study. Figure 4 indicates that the mean voltage for the filtering method is $0.2768 \mathrm{~V}$ with a regression value of 0.934 and for the soaking method, there was $0.1532 \mathrm{~V}$ mean voltage with a regression value of 0.9076 , respectively. Then, the standard deviation (SD) for the filtering method is 0.100633 and the soaking method is 0.04316 . Statistical analysis was run using Oneway Anova and results showed that the output voltages based on these different methods were significant,with the p-value was 0.0002605 less than $\alpha=0.05$. The graph in Figure 4 demonstrates that the energy produced is dependent on the method used to get the fish wastes. The result showed that between the filtering method and soaking method, the higher the number of fishes in the tanks, the higher the amount of voltage could be measured through the filtering method rather than the soaking method. 


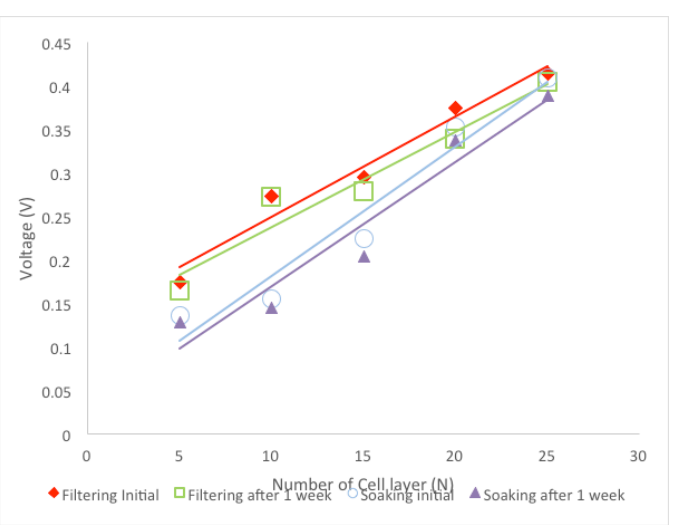

Figure 5: Electrical energy output (voltage) with the different methods used.

\section{Comparison graph between the filtering and the soaking method based on the different number of the cell layers}

Figure 5 represents the electrical energy output (voltage) against the number of cell layers between methods involved in this observation. Figure 5 shows the mean voltage for the filtering method is $0.3066 \mathrm{~V}$ with a regression value of 0.9653 and for the soaking method is $0.2558 \mathrm{~V}$ with the regression value of 0.9489 , respectively. Then, the standard deviation (SD) for the filtering method is 0.09318 and the soaking method is 0.1206 . Also, statistical analysis was run using One-way Anova and results indicated that the output voltages based on these different methods were significant with the p-value was 0.0002897 less than $\alpha=0.05$. The graph in Figure 5 shows that the energy produced is dependent on the method used to get the fish wastes. The result showed that between the filtering method and soaking method, the higher the number of fishes in the tanks, the higher the amount of voltage could be measured through the filtering method rather than the soaking method.

\section{Discussion}

Electrical energy output in voltage was successfully measured from the fish waste of C. Gariepinus species. The fishes were cultured for one week by differentiating variables for the number of fishes, the number of cell layers and method used to observe the electrical energy output in voltage. The amount of ammonia excreted by the fish varies depending on the amount of feed put into the pond or culture system whereby it increases as feeding rates are increased (Durborow et al., 1997). An increase in ammonia was the main focus in this study and it is known as a natural resource that can be used as renewable energy that produces electricity. Most of the bony fishes could continuously excrete ammonia whenever being fed and this has added advantage due to the conversion of urea to ammonia was being observed (Altinok \& Grizzle, 2004). Many emerging waste management technologies that convert waste to energy require advanced process design and integration (Garcia \& You, 2017). The physical factors of fish such as length and weight could also influence the result, combined with the time for feeding, and total feeding weight given could also affect the amount of waste (Unit et al., 2018). Those influencing factors were controlled in this study to ensure the accurate results.

Figures 4 and 5 show graphical data recorded according to analysis results based on the method used. The findings showed that the filtering method had more significant results where output voltages are higher against the different numbers of fish and cell layers. Solid waste coming from fish wastes has the potential capability to produce biofuels, bioenergy and biobased materials (Greggio et al., 2018). Waste would be the most beneficial source of clean and important energy and it could be a substitute for the declining primary energy sources (Pavlas et al., 2015). The amount of waste that keeps increasing from time to time needs to be controlled and recycled to achieve the ultimate goal of global waste management (Brunner \& Rechberger, 2015). Human activities would also cause lots of waste production. The higher the material turnover and the more the materials are produced, the more challenging for waste management to reach the goals for a sustainable country (Brunner \& Rechberger, 2015). 
The results from this experiment were differentiated based on numbers of fish, numbers of cell layers, time period and electrical energy output in voltage. The mean voltages shown in Figures 4 and 5 are higher which confirms that both the objectives of this study are achieved and could be concluded that the filtering method produces the highest voltage in accordance with the number of fishes. This is due to the amount of the filtered hydrogen ion inside that was more than the amount being absorbed through the soaking method.

\section{Conclusion}

As a conclusion, the electrical energy output in voltage from the fish waste of Clarias gariepinus produced different results according to the different tests between the number of fishes (which $\mathrm{N}=10,20,30,40,50$ ) with the highest voltage recorded was from the tank with 50 fishes that produced around $0.4 \mathrm{~V}$. As for observations on number of the cell layers, results showed that the highest was 25 layers from the same number of fishes that collected the same amount of produced voltage that is around $0.4 \mathrm{~V}$. Thus, it can be concluded that the energy output depends on the number of fishes and the number of cell layers along with the time period. The method that was significant to be applied to achieve a higher amount of voltage was the filtering method because the higher amount of voltage recorded was increasing in both filtering method for different objectives for the number of the fishes and the number of the cell layers.

\section{Acknowledgements}

The author would like to express appreciation to the Faculty of Fisheries and Food Science, Universiti Malaysia Terengganu for the provision of research facilities and technical supports throughout the execution of this final year project.

\section{References}

Altinok, I., and Grizzle, J. M. (2004). Excretion of ammonia and urea by phylogenetically diverse fish species in low salinities, 238, 499-507. https://doi.org/10.1016/j. aquaculture.2004.06.020

Brunner, P. H., \& Rechberger, H. (2015). Waste to energy - key element for sustainable waste management. Waste Management, 37, 3-12. https://doi.org/10.1016/j. wasman.2014.02.003

Durborow, R. M., Crosby, D. M., \& Brunson, M. W. (1997). Ammonia in Fish Ponds, (463).

Greggio, N., Carlini, C., Contin, A., Soldano, M., and Marazza, D. (2018). Exploitable fish waste and stranded beach debris in the Emilia-Romagna Region ( Italy ). Waste Management, 78, 566-575. https://doi. org/10.1016/j.wasman.2018.06.034.

Kumar, A., \& Samadder, S. R. (2017). A review on technological options of waste to energy for effective management of municipal solid waste. Waste Management, 69, 407-422. https://doi.org/10.1016/j. wasman.2017.08.046

Lazaroiu, G., Pană, C., Mihaescu, L., Cernat, A., Negurescu, N., Mocanu, R., \& Negreanu, G. (2017). Solutions for energy recovery of animal waste from leather industry. Energy Conversion and Management, 149, 1085-1095. https://doi.org/10.1016/j. enconman.2017.06.042

Olabi, A. G. (2016). Hydrogen and Fuel Cell developments: An introduction to the special issue on "The 8th International Conference on Sustainable Energy and Environmental Protection (SEEP 2015), 11-14 August 2015, Paisley, Scotland, UK." International Journal of Hydrogen Energy, 41(37), 16323-16329. https://doi. org/10.1016/j.ijhydene.2016.07.235 
Olabi, A. G. (2017). Renewable energy Zhang, J., Zhao, J., Yue, L., Wang, Q., Chai, and energy storage systems. Energy, J., Liu, Z., ... Chen, L. (2015). Safety136, 1-6. https://doi.org/10.1016/j. Reinforced Poly(Propylene Carbonate)energy.2017.07.054

Pavlas, M., Fusek, M., Klimek, P., and Touš, M. (n.d.). Waste-to-Energy Systems Modelling Using In-House Developed Software, 1-6.

Unit, A., River, C., and Development, B. (2018). Based All-Solid-State Polymer Electrolyte for Ambient-Temperature Solid Polymer Lithium Batteries. Advanced Energy Materials, 5(24), 1-10. https://doi. org/10.1002/aenm.201501082

GSJ : Volume 6, Issue 9 , September 2018, Online : ISSN 2320-9186. 6(9), 589-612. 